\title{
Vesico-vaginal fistula as a complication of total laparoscopic hysterectomy: a case report and literature review
}

\author{
Latika Sahu*, Gauri Gandhi, Shubhra Singh
}

Department of Obstetrics \& Gynecology, Maulana Azad Medical College and associated Lok Nayak Hospital, New Delhi, India

Received: 1 July 2013

Accepted: 11 July 2013

*Correspondence:

Dr. Latika Sahu,

E-mail: latikasahu@gmail.com

(C) 2013 Sahu L et al. This is an open-access article distributed under the terms of the Creative Commons Attribution Non-Commercial License, which permits unrestricted non-commercial use, distribution, and reproduction in any medium, provided the original work is properly cited.

\begin{abstract}
Complications are possible in all type of surgeries including hysterectomy irrespective of the route of surgery, experience of the operating surgeon or the associated risk factors present. If the surgeon is careful from the beginning of the surgery and follows all the preventive measures complications like urinary tract injuries and vesico-vaginal fistula formation following hysterectomy can be avoided. Here we are presenting a case of vesico-vaginal fistula formed following total laparoscopic hysterectomy (TLH) and reviewed literature regarding incidence, preventive measures for this complication.
\end{abstract}

Keywords: Vesicovaginal fistula, Laparoscopic hysterectomy, Complication

\section{INTRODUCTION}

Total hysterectomy for benign lesions is one of the frequent surgeries in women. ${ }^{1}$ Most hysterectomies are done by laparotomy but laparoscopic hysterectomies are increasing these last years. ${ }^{2,3}$ In Total laparoscopic hysterectomy (TLH) the entire operation is performed laparoscopically and there is no vaginal component. ${ }^{4}$ Reich reported the first case of TLH in $1989 .{ }^{5}$ Laparoscopic hysterectomy is indicated when the vaginal route is potentially difficult because of an immobile uterus or a poor vaginal accessibility. ${ }^{6}$ By 1996 TLH in Finland, France, USA and UK was 24\%, 13.2\%, 9.9\% and $3 \%$ respectively of all hysterectomies and in Denmark by 2000 , it was $6 \% .^{2,7-10}$

This operation requires the highest degree of surgical skill. Bladder injury is one of the intra-operative complications of TLH and if undiagnosed can develop post-operative vesico-vaginal fistulas (VVF). The bladder injuries after hysterectomies can be detected if a cystoscopy is performed at the end of surgery. ${ }^{11,12}$
The benefit of laparoscopy over laparotomy is well known. ${ }^{13}$ A meta-analysis demonstrated that in laparoscopy there is the increased risk of urologic complications upon which bladder injuries are the most frequent. ${ }^{7,13-15}$ Here we report a case of bladder injury during TLH by probably an inexperienced surgeon which if could have detected in proper time morbidity of the patient could have reduced.

\section{CASE REPORT}

A 39 year old lady from upper middle class socioeconomic status admitted to gynaec ward with complaints of dribbling of urine per vaginum starting on post-operative day 7 of TLH done at private hospital, for fibroid uterus 6 month back. There was history of prolonged catheterization for 15 days, intraabdominal drain kept till day 10, intermittent dribbling of urine per vaginum since post-operative day 7 with Foley's catheter in situ. She had continuous dribbling of urine per vaginum after catheter removal. She had sensation of bladder fullness, and was able to void per urethra. There was no h/o of fever, 
abdominal distention/pain, urgency/abnormal urinary stream, hematuria / suprapubic pain/flank pain/ burning micturition in post-operative period. She did not have fever/ discharge per vaginum or bowel complaints. She was para 2 and her $1^{\text {st }}$ child was by vaginal delivery at hospital, $2^{\text {nd }}$ child was 15 yrs back cesarean section at private hospital, tubal ligation done 13 years back. Her BMI was $23.2 \mathrm{~kg} / \mathrm{m}^{2}$. Her vitals and systemic examination was normal. On per abdomen examination-Infraumblical vertical right parmedian scar and five port site scar of TLH present.

Local Examination: Excoriation marks present on labia majora. Per speculum examination in dorsal lithotomy position showed a defect of $3-5 \mathrm{~mm}$ at left side of vaginal vault, margins not seen clearly. Same defect 3-5 mm felt at left vaginal vault with puckering of vaginal mucosa transversely and surrounding fibrosis.

Investigations: Three swab test, top and middle swab stained blue indicative of high VVF. Renal function tests were within normal limits, Urine routine \& culture -3 samples sterile, Cystourethroscopy: A fistulous tract of 3 $5 \mathrm{~mm}$ seen $1.5 \mathrm{~cm}$ above interureteric ridge. Catheter put through vagina seen coming out of the fistulous tract. No ureteric involvement. Intravenous urography: Bilateral kidney, pelviccalyceal system, ureter normal, Urinary bladder partially distended shows faintly contrast opacified tract between bladder and vagina.

She was operated by transperitoneal and transvesical repair of fistula and postoperatively suprapubic and transurethral foley's catheter was put. Transurethral catheter was removed on postoperative day 14 and suprapubic catheter was removed on day 21 . She was given antibiotics peri-operatively and was continent and able to void urine normally. At six week follow up she was continent and healthy.

\section{DISCUSSION}

Bladder injury is linked to anatomic considerations as TLH needs vesico-uterine pouch dissection, when a bladder injury may occur. The risk factors are previous cesarean section/laparotomy, no previous vaginal delivery. Armenakas and colleagues reviewed 65 patients in whom intraoperative bladder cystotomy was identified and immediate repair was accomplished with the success rate of $98.4 \% .{ }^{16}$ However, an unrecognized cystotomy or partial tear of the bladder muscularis or avascular necrosis secondary to crush injury may lead to VVF. Animal studies showed, an electrosurgically induced cystotomy and repair of the bladder during TLH is associated with formation of VVF postoperatively. ${ }^{17}$

Tea H.I. Brummer et al in their study showed incidence of VVFs during 2000-2005 was $0.16 \%$. There were 22 VVFs. Two fistulas treated by Foley catheter drainage and by electrocoagulation via cystoscopy and 20 were repaired by laparotomy. Four patients had multiple laparotomies, for VVF repairs. ${ }^{18}$ Double-layer repair appears to be superior to single-layer repair for the prevention of VVF after monopolar cystotomy. ${ }^{19}$

The rate of bladder injuries during TLH of most study series is given in the table. In Canadian and FINHYST study $18 \%$ and $82 \%$ of bladder injuries were discovered intra-operatively. ${ }^{12,20}$ A large prospective study in Norway gives $1.3 \%$ of bladder injuries for TLH, which decreases from $2 \%$ for the first 30 procedures to $0.8 \%$ after 30 procedures. $^{7}$ Marie-Christine et al had $2 \%$ in the first 40 procedures of all surgeons and $0.4 \%$ for the hysterectomies performed after 100 cases of the surgeons' experience. The rate of bladder injuries during TLH decreases when the learning curve is excluded and the risk factors are controlled.

Table 1: Studies showing bladder injuries during TLH.

\begin{tabular}{|c|c|c|c|}
\hline Authors & $\begin{array}{l}\text { Publication dates } \\
\text { (surgery dates) }\end{array}$ & Type of studies & $\begin{array}{l}\text { Bladder injuries of TLH, } \\
\%(n / N)\end{array}$ \\
\hline Harkki-Siren et al. & $1998(1990-1995)$ & National register & $0.88 \%(24 / 2741)$ \\
\hline Cosson et al. ${ }^{22}$ & $2001(1991-1998)$ & Retrospective & $0.5 \%(1 / 190)$ \\
\hline Garry et al. & $2004(1996-2000)$ & $\begin{array}{l}\text { Multicentric randomized study } \\
\text { (eValuate study) }\end{array}$ & $0.9 \%(3 / 336), 2.1 \%(12 / 584)$ \\
\hline Vakili et al. & $2005(2000-2003)$ & Prospective multicentric study & $2 \%(1 / 49)$ \\
\hline $\mathrm{Ng}$ et $a l^{23}$ & $2007(2001-2005)$ & Retrospective study & $0.2 \%(435)$ \\
\hline Johnston et al. & $2007(2005)$ & Prospective multicentric study & $0.5 \%(2 / 364)$ \\
\hline David-Montefiore et al. & 2007 (2004) & Prospective multicentric study & $0.8 \%(1 / 121)$ \\
\hline Marie-Christine et al. & 2007 (1993-2007) & $\begin{array}{l}\text { Retrospectively (1993-2000) } \\
\text { Prospectively (2001-2007) }\end{array}$ & $1 \%$ \\
\hline
\end{tabular}


To prevent bladder injures Marie-Christine et al used uterine canulation with anterior vaginal packing which allows the assistant to push the uterus towards promontory to facilitate the dissection between the vaginal and the bladder. In case of difficult dissection, it is possible to visualize the limits of the bladder by filling it through the catheter with methylene blue solution. Hemostasis by bipolar coagulation in the vesico-vaginal space should be done carefully. Some bladder injuries have been described when introducing trocars, the safety rules of introduction have to be followed, particularly avoiding the Pfannenstiel scar. ${ }^{21}$

In the present case the operating surgeon must be an inexperienced for TLH as well as the knowledge of bladder injury management. He could have continued the Foley's catheter for 3 weeks and referred the patient at that time itself for management of VVF. The catheter could have continued for 3 months which itself can close small VVF before the surgery was planned.

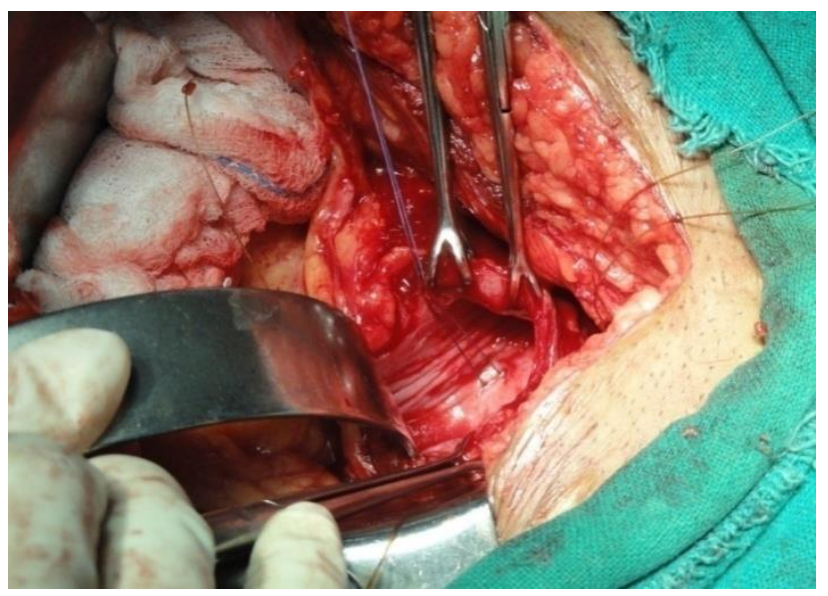

Figure 1: Intraoperative transvesical picture showing VVF above the interureteric ridge (stay suture with vicryl showing the area).

\section{REFERRENCES}

1. Merrill RM, Layman AB, Oderda G, Asche C. Risk estimates of hysterectomy and selected conditions commonly treated with hysterectomy. Ann Epidemiol 2008;18:253-260.

2. Farquhar C, Steiner C. Hysterectomy rates in the United States. Obstet Gynecol2002;99:229-243.

3. David-Montefiore E, Rouzier R, Chapron C, Darai $\mathrm{E}$; Surgical routes and complications of hysterectomy for benign disorders: a prospective observational study in French university hospitals. Hum Reprod 2007;22:260-265.

4. Johnson N, Barlow D,Lethaby A, Tavender E, Curr E, Garry R. Surgical approach to hysterectomy for benign gynaecological disease. Cochrane Database Sys Rev2006;2:CD003677.

5. Reich H. New techniques in advanced laparoscopic surgery. Baillieres Clin Obstet Gynaecol 1989; 3:655-681.
6. Chapron C, Dubuisson JB, Ansquer Y, Gregorakis S $\mathrm{S}$, Morice $\mathrm{P}$, Zerbib M. Bladder injuries during total laparoscopic hysterectomy: diagnosis, management, and prevention. J Gynecol Surg 1995;11:95-98.

7. Mäkinen J,Johansson J, Tomás C,Tomás E, Heinone n PK, Laatikainen T,et al. Morbidity of 10110 hysterectomies by type approach. Hum Reprod 2001;16:1473-1478.

8. Chapron C, Laforest L, Ansquer Y, Fauconnier A, Fe rnandez B, Breart G, DubuissonJB. Hysterectomy techniques used for benign pathologies: results of a French multicentre study. Hum Reprod 1999;14:2464-2470.

9. Maresh MJA, Metcalfe MA, McPherson K, Overton C, Hall V, Hargreaves J, et al. The VALUE national hysterectomy study: description of the patients and their surgery. BJOG 2002;109:302-312.

10. Møller C,Kehlet H, Utzon J, Ottesen B. Hysterectom $\mathrm{y}$ in Denmark. An analyses of postoperative hospitalisation, morbidity and readmission. Dan Med Bull 2002;49:353-357.

11. Vakili B, Chesson RR, Kyle BL, Shobeiri SA, Echols KT, Gist R, et al. The incidence of urinary tract injury during hysterectomy: a prospective analysis based on universal cystoscopy. Am J Obstet Gynecol 2005;192:1599-1604.

12. Gilmour DT, Das S,Flowerdew G. Rates of urinary tract injury from gynecologic surgery and the role of intraoperative cystoscopy. Obstet Gynecol 2006;107:1366-1372.

13. Garry R, Fountain J, Mason S, Hawe J,Napp V, Abb ott J, et al. The eVALuate study: two parallel randomised trials, one comparing laparoscopic with abdominal hysterectomy, the other comparing laparoscopic with vaginal hysterectomy. BMJ 2004;328:129.

14. Chapron C, Fauconnier A, Goffinet F, Bréart G, Dubuisson JB. Laparoscopic surgery is not inherently dangerous for patients presenting with benign gynaecologic pathology. Results of a metaanalysis. Hum Reprod. 2002 May;17(5):1334-42.

15. Harkki-Siren $P$, Sjoberg J, Titinen A. Urinary tract injuries after hysterectomy. Obstet Gynecol 1998;92:113.

16. Armenakas NA, Pareek G, Fracchia JA. Iatrogenic bladder perforations: long term follow-up of 65 patients. J Urol 2005;174(4 Pt 1):1299.

17. Cogan S L, Paraiso MF, Bedaiwy MA. Formation of vesicovaginal fistulas in laparoscopic hysterectomy with electrosurgically induced cystotomy in female mongrel dogs. Am J Obstet Gynecol 2002 Dec;187(6):1510-4.

18. Brummer TH, Seppälä TT, Härkki PS. National learning curve for laparoscopic hysterectomy and trends in hysterectomy in Finland 2000-2005. Hum Reprod. 2008 Apr;23(4):840-5.

19. Sokol AI, Paraiso MF, Cogan SL, Bedaiwy MA, Escobar PF, Barber MD. Prevention of vesicovaginal fistulas after laparoscopic hysterectomy with 
electrosurgical cystotomy in female mongrel dogs Am J Obstet Gynecol.2004 Mar;190(3):628-33.

20. Tea H.I. Brummer, Jyrki Jalkanen, Jaana Fraser, Anna-Mari Heikkinen, Minna Kauko, Juha Mäkinen, Tomi Seppälä, Jari Sjöberg, Eija Tomás, and Päivi Härkki. FINHYST, a prospective study of 5279 hysterectomies: complications and their risk factors. Hum Reprod. 2011;26(7):1741-51.

21. Marie-Christine Lafay Pillet, Franck Leonard, Nicolas Chopin, Jean-Marie Malaret, Bruno Borghese, Hervé Foulot, Adolphe Fotso, and Charles Chapron. Incidence and risk factors of bladder injuries during laparoscopic hysterectomy indicated for benign uterine pathologies: a 14.5 years experience in a continuous series of 1501 procedures. Hum Reprod. 2009;24(4):842-9.

22. Cosson M, Lambaudie E, Boukerrou M, Querleu D, Crepin G. Vaginal, laparoscopic, or abdominal hysterectomies for benign disorders: immediate and early postoperative complications. Eur J Obstet Gynecol Reprod Biol 2001;98:231-6.

23. Ng CC, Chern BS, Siow AY. Retrospective study of the success rates and complications associated with total laparoscopic hysterectomy. J Obstet Gynaecol Res 2007;33:512-8.

DOI: $10.5455 / 2320-1770 . i j r \operatorname{cog} 20130947$

Cite this article as: Sahu L, Gandhi G, Singh S. Vesico-vaginal fistula as a complication of total laparoscopic hysterectomy: a case report and literature review. Int J Reprod Contracept Obstet Gynecol 2013;2:463-6. 